Dept. of Sciences, Fac. of Agricultural and Veterinary Sciences, University of Tiaret, Algeria.

\title{
E. COLI ANTIBIORESISTANCE IN BROILER CHICKEN WITH COLLIBAQCILLOSIS
}

(With 3 Tables)

By

\section{A. HAMMOUDI; A. MOUATS and H. AGGAD*}

* Dept. of Sciences, Fac. of Agricultural and Veterinary Sciences, University of Mostaganem Algeria.

(Received at 14/3/2007)

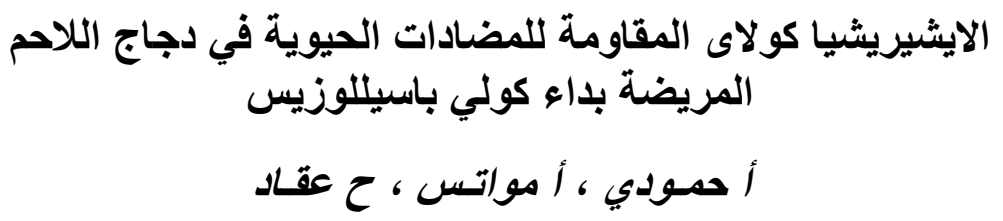

تم عزل مائتين وواحد وخمسون سلالة Escherichia coli من دجاج في غرب الجي الجزائر.

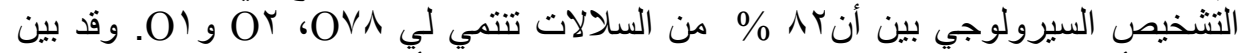

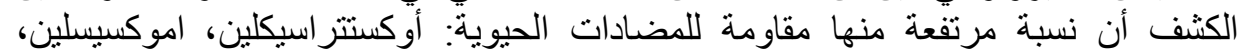

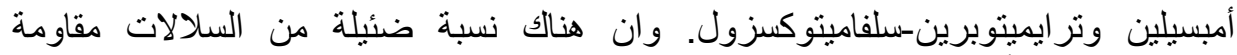

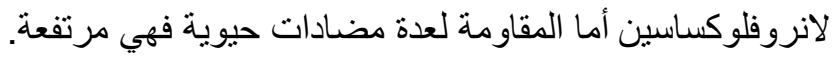

\section{SUMMARY}

Two hundreds and fifty one Escherichia coli isolates were recovered from broilers with clinical signs and lesions of colibacillosis in the West area of Algeria. Serotyping showed that $82 \%$ of the isolates belong to one of the serotypes $\mathrm{O} 78, \mathrm{O} 2$ and $\mathrm{O} 1$. Antibiograms revealed a high level of resistance to oxytetracycline, amoxicilline, ampicilline, and trimethoprim-sulfmethoxazole. However, only a low percentage of strains was resistant to enrofloxacine and muti was common.

Key words: Escherichia coli, antibioresistance, colibacillosis, Algeria, poultry.

\section{INTRODUCTION}

Among bacterial infections colibacillosis is a worldwide major cause of morbidity and mortality in poultry and is responsible for significant economic losses to the poultry industry. Stordeur and Mainil (2002) reported the causative bacteria, avian pathogenic Escherichia coli 
(APEC) induce various syndromes including respiratory tract infection (airsacculitis), acute colisepticemia, salpingitis and cellulitis. The most common form of colibacillosis occurs among 3 to 10 weeks-old chickens. It is characterized by an initial respiratory infection usually induced by mycoplasmal and/or viral infections and enhanced by a high level of ammoniac in poultry houses. The disease evolves as a systemic infection (perihepatitis, pericarditis and septicaemia) due to the invasive abilities of the Escherichia coli strains (Dho-Moulin and Fairbrother, 1999).

Numerous studies have shown that APEC strains usually belong to serogroups O1, O2 and O78 (Blanco et al., 1997; Ngeleka et al., 2002) but other serogroups can also be identified.

In Algeria, avian colibacillosis is responsible for large economic losses in poultry breeding resulting in low performances, weight loss, onset of egg production and mortality. This has led to an intensive use of antibiotics resulting in an unavoidable loss of efficacy of treatments. In the absence of epidemiologic data allowing a survey of antibiotic resistances, the use of antibiotics remains quite irrational. In an effort to get a better knowledge of the antibioresistance status of APEC we have collected and characterised strains from cases of avian colibacillosis.

\section{MATERIALS and METHODS}

Sampling site and procedure: The study was conducted in the Western area of Algeria (Oran, Mostaganem, Tiaret). Thirty broiler chick flocks with large capacity (between twenty thousand to thirty thousand broilers) in the Western area of Algeria were selected.

Random samples were taken from broiler clinically affected with colibacillosis and showing characteristic lesions at necropsy. A total of $251 \mathrm{E}$. coli isolates were collected from broilers 4 to 7 weeks-old during colibacillosis outbreaks.

Culture and biochemical characterisation: Visceral organs liver, spleen and heart blood were cultured on Drigalski agar (SanofiDiagnostics Pasteur, France) and incubated aerobically at $37^{\circ} \mathrm{C}$ for 18 to $24 \mathrm{~h}$. Suspected $E$. coli colonies were subsequently inoculated on eosinemethylene blue agar (Bio Mérieux, France) and incubated at the same time and temperature described previously. The identification of E. coli was used according the results of diagnostic tests, including Gram stain, catalase and oxidase (Quinn et al., 1994). 
Metabolic profiles were analysed for each isolate using API system (Bio Mérieux, France) used for the identification of Enterobacteriaceae.

Serotyping: Serotype was determined by agglutination test with specific antiserum raised against $\mathrm{O} 1: \mathrm{K} 1, \mathrm{O} 2: \mathrm{K} 1$ and $\mathrm{O} 78$ antigens (Biovac, Angers, France and LDA22, Ploufragan, France) according to Finazzy et al. (2000).

Antimicrobial sensitivity: Antibiotic sensitivity was determined by the disc diffusion method on solid medium of Mueller-Hinton (SanofiDiagnostics Pasteur, France) according to the guidelines of the "Comité de l'Antibiogramme de la Société Française de Microbiologie".

Oxytetracycline, Ampicillin, Amoxicilline, Trimethoprimsulfamethoxazole, Oxolinic, acid Flumequine, Enrofloxacine, Colistine standard paper disk were laid on the medium.

Commercial antibiotic disks were purchased from SanofiDiagnostics Pasteur. Enrofloxacin was provided by Bayer. The plates were incubated for $24 \mathrm{~h}$ at $37^{\circ} \mathrm{C}$ and inhibition zones measured.

Statistical analysis: Pearson coefficient correlation was used to compare the frequency of associated antibioresistance.

\section{RESULTS}

Post-mortem examination: The observed lesions at necropsy were characteristic of colibacillosis and were in decreasing frequency: pericarditis, perihepatitis, tracheitis, airsacculitis and nephritis.

Culture, biochemical and serological identification: Isolates were catalase positive, oxydase negative and had a dark green, black metallic sheen on eosin-methylen blue agar. The API commercial differentiation system identified all the strains isolated as E. coli.

E. coli. $\mathrm{O} 78$ and $\mathrm{O} 2: \mathrm{K} 1$ were mainly isolated 110 (44\%) and 73 (29\%) respectively, O1:K1 represented $23(9 \%)$ of the isolates. The reamains $45(18 \%)$ of the isolates did not belong to these three serotypes.

Resistance frequencies: The resistance frequencies (RF) for each antibiotic tested are shown in Table 1 . Most of the strains were resistant to oxytetracycline $(82 \%)$, and nearly the half $(47 \%)$ were resistant to ampicillin and amoxicilline and trimethoprim-sulfamethoxazole (42\%). A high frequency of resistance (31\%) was also observed to oxolinic acid and flumequine. However the resistance to fluoroquinolone (enrofloxacin) and to colistine was unfrequent ( $6 \%$ and 3 respectivelly). 
Significant differences in the resistances associated with the serotypes were only observed for oxytetracycline and ampicillin. Strains belonging to the $\mathrm{O} 78$ serotype or to nonidentified serotypes were more frequently resistant to oxytetracycline and/or to ampicillin than $\mathrm{O} 1: \mathrm{K} 1$ and $\mathrm{O} 2: \mathrm{K} 1$ strains.

Multiresistance: The percentage of resistant isolates was high: 98\%. A total of $93 \%$ were resistant to at least 2 antibiotic and $22 \%$ were resistant to at least 4 antibiotics. About $10 \%$ of isolates are resistants to five or six antibiotics (Table 2). However only the trend of resistance of isolates for oxytetracyclin and ampicillin were relatively significant $(r=0.44)$ followed by oxolonic acid and enrofloxacine $(r=0.33)$ than ampicillin and enrofloxacine flumequine (0.31).

Antibiotypes: A total of 52 antibiotypes could be distinguished. The most frequent are those designated in Table 3 as i, h, b, k and c. A total $(3.58 \%)$ of strains are resistant only for oxolinic acid. A percentage of $6.77 \%$ and $4.38 \%$ of strains are resistant to oxytetracycline.trimetoprimsulfamethoxazole and ampicillin.oxytetracycline respectivelly. A high level of multiresistance (27.4\%) was observed for 3 antibiotics: 9.16 for ampicillin. oxytetracycline. amoxicilline, 13.54 for ampicillin. flumequine. oxytetracycline and 4.78 for trimetoprim-sulfamethoxazole. oxytetracycline. amoxicilline. However $3.98 \%$ of strains are resistant to 5 antibiotics (flumequine. ampicillin. amoxicilline. oxytetracycline. oxolonic acid).

Table 1: Antibioresistance of $E$. coli strains isolated.

\begin{tabular}{|l|c|c|c|c|c|}
\hline & \multicolumn{5}{|c|}{ Number of resistant strains (\%) } \\
\hline Antibiotic $(\mu \mathrm{g})$ & $\mathrm{O} 78$ & O2:K1 & O1:K1 & Other serotypes & Total \\
\hline Oxytetracycline (30) & $104(95)$ & $50(69)$ & $13(57)$ & $39(87)$ & $206(82)$ \\
\hline Ampicillin (10) & $63(57)$ & $29(40)$ & $5(22)$ & $21(47)$ & $118(47)$ \\
\hline Amoxicilline (20) & $63(57)$ & $28(38)$ & $6(26)$ & $21(47)$ & $118(47)$ \\
\hline $\begin{array}{l}\text { Trimethoprim } \\
\text {-sulfamethoxazole (25) }\end{array}$ & $54(49)$ & $23(31)$ & $7(30)$ & $22(49)$ & $106(42)$ \\
\hline Oxolinic acid (10) & $36(33)$ & $23(31)$ & $5(22)$ & $15(33)$ & $79(31)$ \\
\hline Flumequine (30) & $36(33)$ & $23(31)$ & $5(22)$ & $14(31)$ & $78(31)$ \\
\hline Enrofloxacine (50) & $7(6)$ & $4(5)$ & $2(9)$ & $1(2)$ & $14(6)$ \\
\hline Colistine (10) & $2(2)$ & $2(3)$ & $2(9)$ & $1(2)$ & $7(3)$ \\
\hline Total number of isolates & 110 & 73 & 23 & 45 & $251(100)$ \\
\hline
\end{tabular}


Table 2: Strains of E. coli showing multiresistance.

\begin{tabular}{|cl|}
\hline $\begin{array}{l}\text { Number of antibiotics } \\
\text { Out of } 8 \text { tested }\end{array}$ & Percentage of strains resistant \\
\hline 0 & 2 \\
1 & 6 \\
2 & 25 \\
3 & 45 \\
4 & 12 \\
$\geq 5$ & 10 \\
\hline
\end{tabular}

Table 3: The most frequent antibiotic resistance patterns in E. coli strains.

\begin{tabular}{|lcc|}
\hline Resistance patterns & Designation & Percentage of strains \\
\hline OXA & $\mathrm{A}$ & 3.58 \\
OT.TMS & $\mathrm{B}$ & 6.77 \\
AMP.OT & $\mathrm{C}$ & 4.38 \\
OXA. OT & $\mathrm{D}$ & 2.39 \\
AMO.OXA & $\mathrm{E}$ & 2.39 \\
AMP.TMS. OT & $\mathrm{F}$ & 3.98 \\
OT.AMO.TMS & $\mathrm{G}$ & 2.39 \\
AMP. OT.AMO & $\mathrm{H}$ & 9.16 \\
AMP.FLU. OT & $\mathrm{I}$ & 13.54 \\
AMP.TMS.OXA & $\mathrm{J}$ & 2.78 \\
TMS. OT.AMO & $\mathrm{K}$ & 4.78 \\
OT.AMP.AMO.TMS & $\mathrm{L}$ & 2.39 \\
AMO.OT.OXA.FLU & $\mathrm{M}$ & 2.39 \\
AMO.TMS. OT.ENR & $\mathrm{N}$ & 2.39 \\
FLU.AMP.AMO.OT.OXA & $\mathrm{O}$ & 3.98 \\
TOTAL & & 67.33 \\
\hline
\end{tabular}

OXA oxolonic acid, OT oxytetracycline, TMS trimetoprim-sulfamethoxazole, AMP ampicillin, AMO amoxicilline, FLU flumequine, ENR enrofloxacine.

\section{DISCUSSION}

A high resistance has been retained to three antibiotics: oxytetracycline, ampicillin and amoxicilline (Table 1). In view of the whole range of antibiotics available in Algeria and the lack of legislative restrictions on their use for therapy, prophylaxis or growth promotion, the globally high incidence of antibiotic resistance observed in the present study is not surprising. Resistances to ampicillin, trimethoprimsulfamethoxazole, oxolinic acid and flumequine were far higher than in other studies (Amara et al., 1995; Blanco et al., 1997; Ngeleka et al., 2002). The percentage of resistant bacteria to oxytetracycline was the highest (82\%) as observed in Marroco by Filali et al. (Filali et al., 1988). 
However, resistance to enrofloxacine and colistine remained at a low level, reflecting the unfrequent use of this antibiotic in poultry breeding in Algeria.

Multiresistance appeared as a veritable problem as the majority of strains $(63.7 \%)$ was resistant to at least two antibiotics.

This indicates that the abusive and anarchic use of antibiotic is probably at the origin of the high incidence of antibioresistances and of multiresistances of $E$. coli in poultry breeding in Western Algeria. Such practices, especially without prior antibiotic sensitivity testing of bacterial isolates may lead to the development of a pool of antibioticresistant genes and to the selection of increasing numbers of resistant $E$. coli clones. This first study should constitute a basic reference for further surveys of antibiotic-resistance of $E$. coli isolates in the Western Algeria. The evolution of antibiotic-resistance of avian E. coli, together with the evolution of therapeutic practices should be controlled by a network of epidemiological survey of poultry breeding in Algeria.

\section{CONCLUSION}

The problem of antibiotic-resistances of avian E. coli isolates is of particular importance in Algeria where exists a high risk of human contamination because of manual slaughtering of animals. Antibiotic resistances are frequently encoded by conjugative plasmids or transposons, thus $E$. coli of avian origin could act as a possible source for the transfer of antibiotic resistances to other bacterial species including human pathogens (Bebora et al., 1994; Davies, 1994). Thus, an increasing in the reservoir of antibiotic resistant bacteria could heavily impair the treatment of human diseases.

\section{ACKNOWLEDGEMENTS}

We thank M. Dr. Dho-Moulin for reviewing the manuscript.

\section{REFERENCES}

Amara, A.; Ziani, Z. and Bouzoubaa, K. (1995): Antibioresistance of Escherichia coli strains isolated in Morocco from chickens with colibacillosis. Vet. Microbio. 43: 325-330.

Bebora, L.C.; Oundo, J.O. and Yamamoto, H. (1994): Resistance of Escherichia coli strains recovered from chickens to antibiotics with particular reference to trimethoprim-sulfamethoxazole (septrin). East Africa Med. J. 71: 624-627. 
Blanco, J.E.; Blanco, M.; Mora, A. and Blanco, J. (1997): Prevalence of bacterial resistance to quinolones and other antimicrobials among avian Escherichia coli strains isolated from septicemic and healthy chickens in Spain. J. Clin. Microbio. 35: 2184-85.

Davies, J. (1994): Inactivation of antibiotics and the dissemination of resistance genes. Science 264: 375-382.

Dho-Moulin, M. and Fairbrother, J.M. (1999): Avian pathogenic Escherichia coli (APEC). Vet. Res.; 30: 299-316.

Filali, E.; Bel, J.G.; El Houdfi, M.; Huggins, M.B. and Coo, J.K.A. (1988): Antibiotic resistance of Escherichia coli strains isolated from chikens with colisepticemia in Morocco. Comp. Immun. Microbio. Infect. Dis. 11: 121-124.

Finazzi, G.; Cardeti, G.; Pacciarini, M.L.; Losio, M. and Tagliabue, S. (2000): Characterization of strains of Escherichia coli isolated from rabbits with enteritis in Lambardia and Emilia Romagna during the triennium 1997-1999. J. World Rab. Sci. Assoc. 8: 241-247.

Ngeleka, M.; Brereton, L.; Brown, G. and Fairbrother, J.M. (2002): Pathotypes of avian Escherichia coli as related to tsh-, pap-, pil-, and iuc-DNA sequences, and antibiotic sensitivity of isolates from internal tissues and the cloacae of broilers. Avian dis. 46: 143-152.

Quinn, P.J.; Carter, M.E.; Markey, B. and Carter, G.R. (1994): Clinical veterinary microbiology. Wolfe Publishing, Spain.

Stordeur, P. and Mainil, J. (2002): La colibacillose aviaire. Annales de Médecine Vétérinaire. 146:11-18. 